\title{
Child-caregiver attachment, self-evaluation and cognitive development in a group of pre-school children
}

\begin{abstract}
Primary attachment relationships have an enormous influence on later cognitive development, socio-emotional development and psychological health. Up to date, no research explored the correlations between the quality of the child-caregiver attachment relationship (AQ), self-evaluation (SE), and cognitive development (CD) of five-year-old pre-school children. In accordance, the aim of this study was to explore the correlation between these three variables. Ten Afrikaans speaking mother-child dyads from white, two parent, first marriage families participated. Participants were assessed with the Pictorial Self-Evaluation Scale (PSES), The Observed Attachment Behavior Q-set (AQS), and The Griffiths Mental Development Scales; Extended Revised (GMDS-ER) in a single study in a South African context. Results indicate that a positive, medium to high practical significant correlations do exist between the reliabilities. However, because of the small number of infants tested, it was difficult in this initial sample to draw firm conclusions about the statistical significance of the results. Nonetheless the results obtained in this pilot study are very encouraging and holds great value for further investigation.
\end{abstract}

Keywords: attachment, early childhood, development, self-evaluation

Marichelle van Deventer, North-West University. E-mail: Marichelle.VanDeventer@nwu.ac.za. Esmé van Rensburg, North-West University.E-mail: Esme.VanRensburg@nwu.ac.za. Paula Sterkenberg, University of Amsterdam. E-mail: Paula.Sterkenburg@hetnet.nl.

South African Journal of Childhood Education | 2011 1(2): 202-227 |ISSN: 2223-7674 | $\odot$ UJ

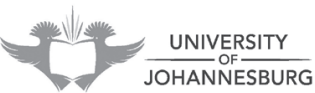




\section{Introduction}

Since the inception of Attachment theory in the 1950s the theory has been open-ended and subject to revision and/or extension (Brisch, 2002; Goldberg, 2000). As Bowlby (1969/1982: 313) stated "attachment theory is still growing: its potential and limitations remain unknown." Attachment theory now combines different contributions from ethology (Ainsworth \& Bowlby, 1991; Bowlby, 1969/1982; 1979/2005), developmental psychology (Bowlby, 1988/2005; Brisch, 2002; Bronfenbrenner, 1986; Kail \& Cavanaugh, 2010; Marvin \& Britner, 2008; Schore, 2001; Sroufe, Carlson, Levy, \& Egeland, 1999), systems theory (Bronfenbrenner, 1986; Diamond, Diamond, \& Hogue, 2007; Marvin \& Stewart, 2008; O'Connor \& Croft, 2001), object-relations theory (Ainsworth,1969), evolutionary psychology (Bakermans-Kranenburg \& van IJzendoorn, 2007; Marvin \& Britner, 2008; O'Connor \& Croft, 2001), cognitive information theory (Bowlby, 1969/1982; Johnson, Dweck, Chen, Stern, Ok, \& Barth, 2010) and psychoanalysis (Bowlby, 1988/2005; Bretherton \& Munholland, 2008) to name a few. The contributions of these fields is as follows: ethology emphasis e the critical developmental issue, that humans have pre-adapted characteristics that predispose them to form attachment in order to survive at each development point; developmental psychology, amongst other things, opened attachment research up to developmental processes and how these processes contribute to children's behaviour in the attachment relationship(s); systems theory drawn attention to regulatory, environmental, biological, and exploratory systems for expanding the scope of attachment theory and research and emphasising that no individual can be understood outside the context in which they function; objectrelations theory made its contribution through the theory of interpersonal relatedness, concerned with the crucial role played by the self and object representations in the conduct of close human relationships; evolutionary psychology made its impact through highlighting the biological bases of attachment behaviour; psychoanalysis contributed by increasingly emphasising the quality of significant early relationships since they are seen to represent the prototype for later interpersonal relationships and to provide the context for the emergence of the self; and cognitive informational theory which propose that the organisation of the attachment behavioural system involves cognitive components, e.g. mental representations of the attachment figure, the self and others. Attachment theory has come to contribute considerably to the understanding of the importance of the quality of the child-caregiver relationship, and its influence on/or relation to numerous other factors ${ }^{1}$ (of which the explanation of over extends the scope of this research) throughout the individual's life cycle, and more specifically, in the shaping of the child (Schore \& Schore, 2008). Children are born with an innate disposition to display attachment behaviour due to the fact that the child is dependent on a nurturer for safety and nurturance (Bowlby, 1969/1982). Typically, preferred attachment appears in the latter part of the first year of life (Boris et al., 2005). To be attached to someone means that one is

strongly disposed to seek proximity to and contact with a specific figure and to do so in certain situations, notably when you are frightened, tired or ill (Bowlby, 1969/1982: 371). 
This organisation of behaviour is known as 'attachment behaviour' and "refers to any of the various forms of behaviour that a child commonly engages in, to attain and/or maintain a desired proximity" (Bowlby, 1969/1982: 371). From an evolutionary based perspective, infants cannot survive without being protected and provided for and this automatically leads to certain goal-directed behaviour by the child for survival (e.g. crying when distressed to obtain the caregiver's attention) (Bowlby, 1969/1982). Children, therefore, obtain a state of homeostasis through their behaviour. Reflecting on the last statement, the attachment system (of the child) can be seen as a biological system, regulating itself to obtain a homeostatic equilibrium status and flexibly adjusting in changing circumstances (De Schipper, Stolk, \& Schuengel, 2006; Schore \& Schore, 2008). In 1951 Bowlby concluded that normal development is promoted by a warm, intimate and lasting relationship between a young child and his or her caregiver. Bowlby claimed that this relationship has important implications for children's concurrent and later social development and, therefore, later relationships (Bowlby, 1969/1982, 1973/1991; Marvin \& Britner, 2008). Patterns of attachment behaviour evolve with development (Ainsworth, 1993; Boris, Aoki, \& Zeanah, 1999; Marvin \& Stewart, 1993; Schneider-Rosen, 1993).

After infancy attachment manifests in different ways ${ }^{2}$, but major concepts such as: internal working models (the inner organisations of attachment), the secure base concept (the starting point for exploration), and the organisation of behaviour in context, continue their value in the view of continuity and change in later development (Ainsworth, 1993). To understand attachment after infancy one has to take into account the rapidly expanding cognitive and affective processes of the developing child and how these interlock with the environmental changes in the child's life. Expansion of attachment theory and other influential factors are of great importance if influences on the individual's life cycle are to be understood.

In line with Bowlby's theory of attachment, Schore and Schore (2008) argue that attachment theory has shifted to a regulatory theory, based on an interdisciplinary development model. Expansion of the attachment theory in this way makes it more clinically relevant, allowing the comprehension and treatment of disorders of the self and affect regulation more effective (Schore \& Schore, 2008).

In the light of contributing to this widely expanded field, the current study's aim was to examine correlations amongst the quality of the child-caregiver attachment relationship (henceforth denoted as AQ), self-evaluation (henceforth denoted as SE), and cognitive development (henceforth denoted as CD) of the child in a sample of 10 child-caregiver dyads in white, two parent, first marriage families. This study wants to emphasis e the importance of high quality primary attachment relationships in infancy, because of its enormous influence on later cognitive development, socio-emotional development and psychological health (DeMuller, Denham, Schmidt, \& Mitchell, 2000; Cicchetti, Cummings, Greenberg, \& Marvin, 1993; Greenberg, Cicchetti, \& Cummings, 1990; Mikulincer \& Shaver, 2007; Thompson, 2008). Ultimately also to contribute to service professionals' knowledge in understanding the importance of the relationship 
between a child and his/her caretaker relating to the level of cognitive development and IWM's of the self. Previous studies have shown that relationships amongst these variables do exist, but no literature could be found combining these variables in a single study. The purpose of this study is to extend prior research in two ways. Firstly, combining these variables in a single study and to explore the correlations amongst them and secondly, by conducting the research in a South African context since research in this domain is almost non-existent.

Before discussing the main variables (namely the quality of child-caregiver attachment relationship, the representation of the self and cognitive development) of this study, it is of utmost importance to discuss an underlying concept of great value to the formation of the attachment relationship.

\section{Internal working models in attachment relationships}

Bowlby centred his ideas of attachment on the concept of 'internal working models' (henceforth denoted as IWM's) that derived from the thinking of psychoanalysis (Bretherton \& Munholland, 2008; Schneider-Rosen, 1993). According to Bowlby (1969/1982), the attachment system utilises cognitive components, specifically mental representations (internal working models [IWM's]), of the attachment figure, the self, and the environment during the child's interaction with the primary caregiver, the child's own actions, and the feedback the child receives from these actions (Cicchetti et al., 1993; Johnson et al., 2010). According to Cassidy (1993), these models are similar to cognitive maps (not permanent or static mental schemes, but flexible models) that permit successful navigation of an organism's environment (Brisch, 2002; Marvin \& Britner, 2008; Mennen \& O'Keefe, 2005). These IWM's contain the "early outlines of the self and how it fits into the social landscape" (Howe, 2005, p. 29). Cassidy (1993) states that the IWM's of the self contain cognitions about one's lovableness and worthiness. Through postulating that the attachment system utilises these cognitive components, explanations can be given of how the child's experiences with the attachment figure come to influence the pattern of attachment the child develops (Bowlby, 1969/1982). Children inevitably extract, from their experiences with their attachment figure, expectations regarding likely behaviour of others and their own behaviour in interpersonal relating (Fairchild, 2006; Howe, 2005; Schneider-Rosen, 1993; Sroufe et al., 1999). These experienced interaction patterns (known as IWM's) are cognitively stored by the children and influence the way children construe their experiences and, therefore, their behaviour (Ainsworth, 1993; Howe, 2005). Once internalised, these IWM's are good guides for children's behaviour, their success in other relationships and for constructing perceptions of themselves (Ainsworth, 1993; Burgess \& MacDonald, 2004; Bretherton \& Munholland, 2008; Howe, 2005; Verschueren \& Marcoen, 2002). Children will, therefore, "approach new situations with certain preconceptions, behavioural biases, and interpretive tendencies" (Sroufe et al., 1999, p. 5). 
The mother's availability during these experiences forms a major part of the IWM the child will store (Johnson et al., 2010; Schuengel, De Schipper, \& Sterkenburg, 2003). When a child has an IWM of the attachment figure as being available, responsive and accessible when needed, a secure attachment occurs. Children are considered to be insecurely attached when they lack such a representation. Secure attachment, therefore, sets a secure base for the child, which fosters exploration, play and other social behaviour (Ainsworth \& Bowlby, 1991; Bretherton \& Munholland, 2008). Smooth, homeostatic integration of the child's attachment behaviour with the attachment figure's caregiving behaviour is a prerequisite for the successful development and operation of this secure base (Bowlby, 1969/1982). According to Marvin and Britner (2008), it is a critical component of the child's rapidly expanding physical and social world to use the attachment figure as a secure base. These exchanges during caregiver and child interaction caused children's IWM's of the self to be intertwined with the ones the child held of the attachment figure (Bowlby, 1969/1982; 1973/1991; 1980). Caregivers, therefore, cannot be seen as the only determining factor of secure attachment, but children can also be seen as an active participant in constructing their own experiences (Sroufe et al., 1999).

Internal working models of infant attachment have shown to have developmental continuity (Fairchild, 2006) and according to Johnson, Dweck \& Chen (2007) these representations can be traced as early as 12 months of age. With maturation and the expansion of experience beyond infancy children develop more complex and differentiated models of self, others and of relationships (Cicchetti et al., 1993), because mental states take centre stage in children's understanding of their and others' actions only at the age of four years (Kail \& Cavanaugh, 2010). As children enter the pre-school years they begin to understand that their attachment figures' goals and motives can differ from their own (Bretherton \& Munholland, 2008; Marvin \& Britner, 2008). When this happens, children can assess situations and plan their behaviour within the framework of these models, therefore, changing the attachment relationship to a goal-corrected partnership (final phase of Bowlby's proposed phases in the development of attachment) (Bowlby, 1969/1982; Johnson et al., 2010). Children are able to feel secure even when the attachment figure is not physically present, only by relying on their secure IWM's (Bretherton \& Munholland, 2008). Ultimately, these IWM's act as filters through which the child's perceptions of social events and expectations regarding relationships are interpreted (Cicchetti et al., 1993; Mennen \& O'Keefe, 2005). These working models can be seen to “influence the overt manifestation of attachment behaviours as children grow older" (Schneider-Rosen, 1993, p. 212). The sustained influence of IWM's after infancy is not without critique and controversy (see Johnson et al., 2010).

\section{Quality of child-caregiver attachment relationship}

The quality of the attachment relationship can be influenced by a number of factors (see Pettit, Bates, \& Dodge, 1997). When considering the quality of the attachment relationship, the interrelation amongst the primary caregiver, the child and the 
environmental aspects (context), e.g. high-stress households, violence, abuse, poverty, etc. (DeMuller et al., 2000; Fairchild, 2006; Mikulincer \& Shaver, 2007) are of great importance. Each of these systems brings a number of influential factors, e.g. the caregiver with his/her sensitivity and responsivity, parenting style, marital quality, and quality of care; the child with his/her temperament, and sex; and the environmental aspect, e.g. a nurturing environment, life events, and family experiences (Brown, Dutton, \& Cook, 2001; DeMuller et al., 2000; Dozier, Stovall, Albus, \& Bates, 2001; Easterbrooks \& Goldberg, 1993; Fairchild, 2006; Kail \& Cavanaugh, 2010; Lyons-Ruth, Alpern, \& Repaeholi, 1993; Mennen \& O'Keefe, 2005; O'Connor \& Croft, 2001; Schuengel \& Janssen, 2006; Sroufe, 1979, 1988). These systemic factors come to influence each other in a complex interactional process that determines the quality of the attachment formed by the child. Both caregiver and child's behaviour can only be understood when "viewed in the context of the child-mother-dyad-as-system" (Marvin \& Stewart, 1993, p. 61).

Consequently one of four distinct patterns of attachment (see Fairchild, 2006; Mennen \& O'Keefe, 2005) is formed, of which a secure attachment can be viewed as the style most beneficial, installing trust and confidence in children (Kail \& Cavanaugh, 2010). Secure and insecure attachment is explained by De Schipper et al. (2006, p. 204) as follows:

Securely attached children flexibly use their caregivers as either a secure base to explore from when conditions are safe or as a safe haven when the child perceives the conditions as dangerous. Insecurely attached children, on the other hand, appear locked in a relationship pattern that either overemphasises independence and exploration (secure base) or dependence and proximity (safe haven).

The quality of a child's attachment has been found to predict "adjustment in many domains, including social, psychological, behavioural and cognitive domains" (Mennen \& O'Keefe, 2005, p. 578). The way in which children view themselves has been identified as one of these domains (Cassidy, 1988; Verschueren, Marcoen, \& Schoefs, 1996).

\section{Attachment quality and representation of the self}

With the attachment relationship between the child and the primary caregiver (the attachment figure), being the first relationship children find themselves to be in, it can be believed to have a significant impact on children's concept of the self. According to Sroufe (1988, p. 19), attachment theory makes its strongest claims on domains like "inner sense of confidence and relationships with others" and "strongly predicts that feelings of efficacy and inner worth should be related to attachment". The self develops not in isolation but in relation to (social) interaction with the environment. One aspect of social interaction, particularly relevant to the formation of the self, is the early interaction with the attachment figure (Bowlby, 1969/1982; 1973/1991; 1980). This relationship with a significant other gives rise to feelings of the self. In early infancy this interaction can be described as an unconscious interactive regulation, which has a lifelong impact on the self (Schore \& Schore, 2008). 
Consistency of the caregiver's behaviour and sensitive responsiveness gives the child some experience and knowledge about his or her ability to act for the self and how they affect others, which theoretically predicts self-esteem (Cassidy, 1993; 2008; Sander, 1976; 1977). Ainsworth (1993) explains this as follows: Children with a secure working model of their relationship with their primary caregiver are assumed to have more positive expectations regarding the caregivers' responsiveness and availability than their insecure counterparts, which will have more negative expectations. Therefore, it is the relation between the expectations (of the child) and the actual availability and responsiveness (of the caregiver) that builds the representation of the specific attachment relationship. Having a positive self-esteem in a securely attached relationship comes as no surprise, because the children feel confident and effective as individuals (Howe, 2005).

These inner representations of the child-caregiver interactions are embodied in the cognition (as IWM's), and are conceived as a "dynamic conception of the characteristics and the behaviour of the attachment figure toward the self (and vice versa)" (Verschueren et al., 1996: 2494). Early IWM's of the self are encoded on an emotive/affective level (Schore \& Schore, 2008) and gives the child an idea of his or her own worth and acceptability as a person in the eyes of the attachment figure (Bowlby, 1973/1991; 1979; Cassidy, 1993). Several studies indicate that a positive and strong connection between the security of the child-primary caregiver attachment representation and the positiveness of self does exist (Cassidy, 1993; Vékony, Van Aggelen-Gerrits, Van Aken, \& Goudena, 2004; Verschueren \& Marcoen, 1999; Verschueren et al., 1996).

What is not clear at this moment is the extent to which the quality of attachment and the global self-worth of children are related, keeping in mind the possible relation of development in this process in early childhood. Related studies that confirm an existing association/connection between the representation of the self and the representation of the attachment relationship with the primary caregiver have been conducted (Verschueren et al., 1996; Cassidy, 1988). More recent studies (on attachment) focus on the empirical evaluation of the mediational process that may explain the link between attachment security and social functioning and is regarded as high priority (Verschueren \& Marcoen, 2002).

\section{Attachment quality and cognitive development}

Exploration of the attachment formation process (Bowlby, 1969/1982) indicated that interaction between the child and the caregiver forms part of a bigger, more complex cognitive process. Empirical literature suggests that attachment to a primary caregiver may effect different domains of a child's development (Grossmann, Grossmann, Fremmer-Bombik, Kindler, Scheurer-Englisch \& Zimmerman, 2002; Schore \& Schore, 2008; Lyons-Ruth et al., 1993; Mennen \& O’Keefe, 2005; Verschueren \& Marcoen, 1999). According to Schore and Schore (2008) these effects already occur in the preverbal stages of development (Schore \& Schore, 2008). Ainsworth (1993) pointed 
out that cognitive development (after infancy) allows children to part from the primary caregiver for longer periods. According to Janssen, Schuengel and Stolk (2002), the level of a child's cognition plays a vital role in the development of the attachment relationship and later cognitive representations.

Securely attached children are known to be more enthusiastic, persistent, exhibit more positive affect and are more effective in facing environmental challenges on their own than their insecure counterparts (Sroufe, 1979). In other words, the quality of attachment effect once openness to new information, which is important for learning (cognitive development) (Rusk \& Rothbaum, 2010). Infants with disorganised attachment may have deficits in cognitive skills as these children seem to be unable to use the caregiver as a secure base for exploration (Moss, Rousseau, Parent, St-Laurent \& Saintong, 1998).

Attachment research on children with mental retardation associated attachment security with measures of mental development (Schuengel \& Janssen, 2006). According to van IJzendoorn, Goldberg, Kroonenberg and Frenkel (1992), children with a developmental delay are significantly more likely to be classified as insecure. Although studies conducted on animals indicated a relationship between deprivation of a maternal figure or harsh mothering and lower cognitive functioning (De Kloet, Sibug, Helmerhorst \& Schmidt, 2005), interpretation of studies that associate quality of attachment and intellectual disabilities in human beings (see Rutter, O'Connor \& English and Romanian Adoptees (ERA) Study Team, 2004) needs to be done with caution (Schuengel \& Janssen, 2006). However, Schuengel and Janssen (2006, p. 25 ) indicated that relatively high cognitive competence and maternal sensitivity is strongly associated with secure attachment and that "mental development was also significantly and positively associated with AQS security". As mentioned earlier, it is clear that both caregiver and child affect the outcome of the attachment relationship.

\section{Association between the self and cognitive development}

Studies about the self use a wide variety of terminology like self-esteem, self-worth, self-concept, self-competence, and self-evaluation, to name a few, is common. In the current study the focus will be on determining the child's self-evaluation, which could easily be related to self-esteem (Brown et al., 2001). Self-evaluation is a term related to self-affect and describes the value people place on themselves (Cassidy, 1993) and other people's view of their abilities and attributes (Brown et al., 2001). Self-esteem is termed global self-worth by Harter (1990), which descends to the overall value a person places on him or herself. The preceding statement makes it clear that selfevaluation can be viewed as a part of global self-worth.

Harter (1990) asserted that children under the age of eight years possess a sense of self, but do not have the cognitive ability required to verbalise it. Over time more age-appropriate methods, making use of more playful methods of assessment, have been developed to assess younger children's self-representation (Verschueren, Buyck \& Marcoen, 2001). 
When considering self-worth it is necessary to consider actual functioning of the child. Children's subjective evaluation of the self/actual competence may differ from their perceived competence. This argument has been explored on both theoretical and empirical bases by several researchers (see Phillips, 1984; 1987; Schuengel, Voorman, Stolk, Dallmeijer, Vermeer \& Becher, 2006; Verschueren \& Marcoen, 2002). Overly optimistic views of one's actual abilities, for whatever reason, do exist and can influence results obtained by measurements on self-worth. This issue of actual abilities will be considered in this study during the developmental assessment.

Research on intellectual disability by Janssen et al. (2002) indicated that individuals with intellectual disabilities are at risk of developing low self-esteem. According to Carens and Verschueren (2000), low self-esteem in children indicated shying away from challenges, not being proud of one's achievements, and losing interest when frustrated. It could be argued that low self-esteem can influence intellectual ability/ development in a negative way.

In summary the goal of the present study was to examine the correlations amongst $A Q, S E$, and CD. Expectations for this group were as follows:

1. Children with more secure attachment will score higher on global self-worth, thus arguing that the early attachment relationship between a child and a primary caregiver may have an influence on the child's global self-worth (more secure attachment will be positively associated with more positive self-evaluation in this group).

2. In addition it was also expected that more secure attachment would be positively associated with age appropriate cognitive development in this group.

3. Furthermore that more positive self-evaluation will be positively associated with age appropriate cognitive development in this group.

\section{Method}

\section{Participants}

Families were recruited on a voluntary basis through local pre-schools and day-care centres, in Potchefstroom, Republic of South Africa, by means of an availability sampling technique (Schutt, 2006) to participate in the study. Interested families (of all races, Afrikaans and English speaking) were approached. Participants consisted of 12 child-primary caregiver (the mothers identified ${ }^{3}$ themselves as the primary caregiver in all the cases) dyad pairs (pairs consisted of a child and a mother) of which two dyads were excluded on grounds of non-compliance to the selection criteria (a) 4 (Children being too old at the time of testing). The remaining participants came from white, first marriage families. Mothers (all working) had at least 12 years of education and were aged between 33 years to 47 years (Mean age $=36$ years, SD $=4.88$ ). The children ranged in ages 5 years 0 months to 5 years and 11 months (Mean age $=5$ years, 6 months, SD = 3.79). Included in the study were an only child, five children being the 
oldest of two, one youngest of two, two which were the youngest of three children, and one child being the third child of four children. Four children were male and six female and all were Afrikaans speaking. The children attended pre-school/day-care between 12 and 47 hours (SD = 10.60) a week. Family sizes varied between three and six members.

\section{Procedure}

Permission to conduct this study was granted by the Ethics Committee of the NorthWest University; with the ethical clearance number NWU-00034-07-S4. After obtaining the ethical clearance, child-caregiver dyads participated in two evaluation sessions at different times during the period of 11 April 2008 until 23 June 2008. Sessions were scheduled at a time considered to be best by the caregiver. Participants were assessed once only on each of the measurements (Mann, 2003).

The first evaluation at the dyad's home began with the signing of informed consent for research participation. Consent included no foreseeable risk for participation; participant confidentiality through protection of participant identity and the research data; thorough indication of the research goals, purposes, and advantages; and that participation is of an optional nature with no consequences if terminated. All participants were treated in accordance with the Ethical Principles of Psychologist and Code of Conduct (APA, 1992; 2001) and the ethical standards of the SRCD (Society for Research in Child Development [SRCD], 2007). After consent was obtained, demographic data were gathered from the primary caregiver. At the same time the Afrikaans version ${ }^{5}$ (version of their choice) of the PSES was administered to the child (in absence of the primary caregiver). The page containing the pictures is placed in front of the child. A short description is given about the child in the picture after which the child has to indicate which is more like him or her. After a picture is chosen the other picture is closed and the child is asked to what degree he or she is like the child in the chosen picture. To make answering easier, the response categories were visualised as circles underneath the picture of increasing size, with the small circle representing 'sometimes' and the larger circle representing 'hardly ever'. The visit was concluded by the AQS observation and videotaping. The AQS observation was a once off video taping at the dyads home for a period of approximately two hours. The primary caregivers were encouraged to go about their usual activities and to treat the home visitor as they would any other visitor. A number of toys (unknown to the child), provided by the observer, were included for play in the last half hour of observation to obtain a clear picture of the child's orientation towards and interactions with the primary caregiver. Additional reasons for including these toys were to keep the child busy and keep the visit enjoyable. The observer completed sorting and scoring of the items on the same day after watching the tapes. The 90 cards (each with their own rationale (Waters, 1987)) are sorted into nine 10-card piles, from most to least descriptive for the observed dyad. Examples of behaviours described on a single card include, "Child readily shares with mother or lets her hold things if she asks to" and "Runs to mother with a shy smile when new people visit the home". Scores 
obtained by the Q-sorter (a computerised sorting and scoring programme) (Dekker \& Schuengel, 2003-2004) range from -1.0 to +1.0 . The higher the score the more secure the attachment relationship. Security scores were computed by correlating the Q-sort descriptions of an individual with the 90-item criterion Q-sort composite description of a "hypothetically most secure child" (Waters \& Dean, 1985). Due to the lack of trained observers in South Africa, inter-observer reliability scores could not be obtained for this study.

The second evaluation occurred in a standardised testing environment as described in the administration manual of the GMDS-ER (Luiz, Barnard et al., 2006). The visit was a two-hour assessment on cognitive development with the child. Short breaks and knowledgeable alternation between the subscales precluded the possibility of boredom and fatigue. All mothers decided to be absent during the assessment period. Manual scoring took place immediately after administration. A written report of the results was made available to all participating parties.

\section{Measurements}

\section{Assessment of the self}

The Pictorial Self-Evaluation Scale (henceforth denoted as PSES) by Verschueren and Marcoen (1993a) was designed to measure global self-worth in children from 5-7 years of age. Measuring self-concept in children younger than eight years of age has been a difficult task, because of certain stumbling blocks, for example the unresolved questions regarding the nature of self-judgment in early childhood (Cassidy, 1988; 1990) or the ideas about the cognitive limitations of young children to construct a selfesteem or self-worth (Verschueren et al., 2001). Until recently researchers, especially Harter (1990) asserted that children under the age of 8 years possess a sense of self, but do not have the cognitive ability required to verbalise it. Over time more ageappropriate methods, making use of more playful methods of assessment, have been developed to assess younger children's self-representation (Harter \& Pike, 1984; Verschueren et al., 2001). One of the scales central to measuring global self-worth in children, according to Gadeyne, Ghesquière, Onghena and Verschueren (2000), is the Pictorial self-evaluation scale (Zelfbelevingsschaal voor jonge kinderen) that is simple and less time consuming. This pictorial scale taps into children's global self-worth through several questions based on specific domains of functioning (Gadeyne et al., 2000). By using this more age appropriate method of measurement makes this scale suitable for use in early childhood.

This rating scale consists of six items (e.g. "This girl/boy does not like her/himself that much"). Items are based on the General self-worth subscale of Harter's Perceived Competence Scale (Harter, 1982) and the Hand Puppet Interview of Cassidy (see Verschueren \& Marcoen, 1993b). Each item has two pictures; representative of the child's global self-worth of a specific domain of the child's functioning (Gadeyne et al., 2000). Each item is scored on a 4-point scale of which the sum of the six items would 
be representative of the global self-worth as reported by the child (Verschueren \& Marcoen, 1993b).

The English version of the PSES was translated to Afrikaans by a bilingual individual and then back-translated to English where after the original English version were compared with the back-translation and appropriate changes were made.

Cronbach's alpha of 0.82 was obtained by the developers of the scale, indicating internal consistency for the measure; whereas the test-retest reliability was .38 ( $\mathrm{p}<=$ .001) and went up to $.50(p<=.001)$ in a study done by Verschueren et al. (1996) with ninety-five kindergartners aged between 51 and 76 months. Cronbach's alpha and testretest reliability could not be calculated for this study as a result of the small number of participants relative to the number of items in the measurement (Noar, 2003). The scale was not validated in the South African context due to the lack of participants and other relevant scales.

\section{Assessment of attachment security}

The Observed Attachment Behaviour Q-set (Version 3.0) (henceforth denoted as AQS) (Waters \& Deane, 1985) is a standardised method for the naturalistic observation of attachment behaviour between child-caregiver dyads at home or in public places. The AQS consists of 90-items printed on cards that were developed to describe secure base behaviour (Vaughn \& Waters, 1990) of children from age 10 months to 72 months (10 months to 6 years) (Fairchild, 2006).

According to van IJzendoorn, Vereijken, Bakermans-Kranenburg and RiksenWalraven (2004) and Fairchild (2006), the AQS is a valid instrument to assess AQ among the dimension of security-insecurity. Inter-observer reliability indicated a range of scores from .72 to .95/7 respectively, in several other studies (Fairchild, 2006; Solomon \& George, 2008). Due to the lack of trained observers in South Africa, interobserver reliability scores could not be obtained for this study. The researcher was trained in the Netherlands and at completion a reliability score of $85 \%$ were achieved by the researcher. According to Fairchild (2006) professionally trained observers increase reliability and validity of results.

\section{Assessment of cognitive development}

The Griffiths Mental Development Scales - Extended Revised (henceforth denoted as GMDS-ER) (for testing babies and young children from birth to eight years) (Luiz, Barnard et al., 2006; Luiz, Faragher et al., 2006) obtains the child's developmental level (Mental Age (MA)) at the time of testing. The scale for the two to eight year olds measures six domains of functioning, each of which is assessed on a separate subscale. These subscales are; A: Locomotor; B: Personal-Social; C: Language; D: Eye and Hand Coordination; E: Performance, and F: Practical Reasoning. Subscales are separate and complete in themselves and allow assessors to assess the child's development in gross motor skills (A); activities of daily living, interaction and independence (B); receptive and expressive language abilities (C); fine motor skills, manual adroitness and visual 
monitoring skills (D); visuospatial skills (E); and the child's level of general and specific cognitive abilities to problem solving. Each subscale has a number of items that are administered, observed and scored. Scoring can take place manually or by using a computerised scoring programme (Luiz, Foxcroft \& Stewart, 2001).

After revision the GMDS-ER showed continuing validity over time and across cultures (Luiz et al., 2001; Luiz, Barnard et al., 2006; Luiz, Faragher et al., 2006), but further exploration is needed (Luiz, Foxcroft \& Povey, 2006). Inter-observer reliability for MA scores was found to be .97 (intraclass r) by Grantham-McGregor, Stewart and Powell (1991). According to Hogrefe (2008), Cronbach's alpha was calculated for each of the scales, which included all of the items in each of the scales, and exceeded a minimum value of .70 (also see Luiz, Faragher et al., 2006).

An accredited training course by the ARICD (Association for Research in Infants and Child Development) in the administration of the scales was completed by the researcher (Fairchild, 2006).

\section{Data analysis}

To manage and analyse the data obtained in the above-mentioned methods the statistical package, SPSS (Version 15.0) for Windows, was used. To examine correlation between AQ, SE and CD Spearman's rank-order coefficient (Bless \& Kathuria, 1998) were computed on the security scores of the AQS, the average scores of the PSES, and the age equivalent scores obtained from the GMDS-ER. Further correlation analysis was conducted between the three measurements and each of the GMDS-ER subscales scores. Correlations were interpreted and reported in terms of both statistical and practical significance.

Reporting statistical significance of results in seclusion is under escalating criticism (both positive and negative) (Thompson, 1997; 2001; 2002a; 2002b). Statistical significance is not sufficient to evaluate the worth of all research (Thompson, 2002b). Practical significant indexes, called effect sizes, can be reported through various measures (Steyn, 2006; Trusty, Thompson \& Petrocelli, 2004). Literature proposes one of these measures to be based on Spearman's rank correlation (see Ellis \& Steyn, 2007). According to Thompson (2002b, p. 65), it is critical to report effect sizes, "particularly [...] because statistical tests are so heavily influenced by sample size." More recently the APA (2001, p. 25), publication manual ( $5^{\text {th }}$ ed.) emphasised that "it is almost always necessary to include some index of effect size or strength of relationship in your result section."

\section{Results}

Descriptive statistics for the AQS; PSES; GMDS-ER with the six subscales, are presented in Table 1. 
Table 1: Descriptive Statistics $(n=10)$ for the AQS, PSES, GMDS-TR with 6 subscales

\begin{tabular}{|l|c|c|c|c|c|}
\hline & \multirow{2}{*}{ M } & \multirow{2}{*}{ SD } & \multicolumn{2}{|c|}{ Range } & \multirow{2}{*}{ Skewness } \\
\cline { 4 - 6 } & & & Minimum & Maximum & \\
\hline AQS & .24 & .21 & -.19 & .52 & -.84 \\
\hline PSES & 3.61 & .34 & 3.00 & 4.20 & .02 \\
\hline GMDS-TR & 64.95 & 7.50 & 54.00 & 77.00 & .38 \\
\hline GMDS-ER subscales & & & & & \\
\hline A. Locomotor & 65.80 & 9.64 & 42.50 & 79.50 & -1.42 \\
\hline $\begin{array}{l}\text { B. Personal/Social } \\
\text { C. Language }\end{array}$ & 65.65 & 9.87 & 52.50 & 80.50 & .22 \\
\hline $\begin{array}{l}\text { D. Eye-hand } \\
\text { coordination }\end{array}$ & 66.65 & 7.24 & 54.50 & 79.50 & .25 \\
\hline E. Performance & 58.25 & 5.75 & 50.00 & 66.50 & -.12 \\
\hline $\begin{array}{l}\text { F. Practical } \\
\text { reasoning }\end{array}$ & 67.40 & 17.77 & 56.00 & 96.00 & -.11 \\
\hline
\end{tabular}

The central tendency $(M=.24)$ of the AQS security scores is high and the magnitude of skewness is in a negative direction. Security scores show the largest range between scores that could have influenced the mean score of the measurement. According to Bless and Kathuria (1998), extreme high or low scores can affect the mean score. Both the PSES and GMDS-ER scores show a positive direction of skewness, indicating the relatedness between self-evaluation and cognitive development for this group. Ranges of the scores for these two measurements are small with means of 3.61 and 64.95 respectively.

Subscales A, D, and E, of the GMDS-ER, shows a negative direction in the distribution of scores obtained for the 10 participants. Scores of subscales B, C, and F show positive direction of skewness. The preceding indicates that the data for the participants is not equally distributed; therefore Spearman's correlation coefficient was calculated. The central tendencies of scores tend to be moderate for all of the subscales except for the Locomotor subscale. Locomotor scores were affected by extremes in the measurement results. Eye and Hand Coordination show the smallest variation between scores, whereas the Performance subscale shows the largest variation. 
Table 2: Spearman's Correlation $\left(r_{s}\right)$ : Inter-scale correlations

\begin{tabular}{|c|c|c|c|}
\hline & AQS & PSES & GMDS-TR \\
\hline AQS & 1.00 & & \\
\hline PSES & $.40^{\dagger}$ & 1.00 & \\
\hline GMDS-TR & $.46^{\dagger}$ & $.61^{\dagger}$ & 1.00 \\
\hline \multicolumn{4}{|l|}{ GMDS-ER subscales } \\
\hline A. Locomotor & .31 & .35 & $.55^{\dagger}$ \\
\hline B. Personal/Social & $.42^{\dagger}$ & .37 & $.80^{* *}$ \\
\hline C. Language & $.68^{*}$ & $.64^{*}$ & $.77^{* *}$ \\
\hline D. Eye-hand coordination & .14 & $.49^{\dagger}$ & $.84^{* *}$ \\
\hline E. Performance & .29 & $.40^{\dagger}$ & $.90^{* *}$ \\
\hline F. Practical reasoning & $.54^{\dagger}$ & $.56^{\dagger}$ & $.95^{* *}$ \\
\hline $\begin{array}{l}\text { Note: } A Q S=\text { attachment } \mathrm{s} \\
\text { age equivalent mental sco } \\
\dagger r_{s} \approx .5 \\
* \mathrm{p}<.05 \\
* * \mathrm{p}<.01\end{array}$ & es; PSE & If-evalu & ; GMDS-ER = \\
\hline
\end{tabular}

Table 2 shows that although the correlations of the measurements are not statistically significant, practical significant associations are indicated for this group of participants. The small sample size may definitely have been a factor in the nature of findings obtained (Thompson, 2002b; Rosenthal, Rosnow \& Rubin, 2000). Rosenthal et al. (2000) advised that one might make a serious mistake when concluding results amounts to nothing, when confronted with a non-significant $p$ and a large effect size in the case of small samples. Results, henceforth, will be discussed respectively according to practical significance $(\dagger)$ at $r_{s} \approx .5$ (according to Cohen's (1990) effect size guidelines 0.1, 0.3, 0.5; also see Field, 2005; Steyn, 2006) and statistical significance at the .05 level (2-tailed) $(*)$ and the .01 level (2-tailed) $(* *)$.

\section{Correlation between Attachment Quality (AQ) and Self-Evaluation (SE) (see Table 2)}

Correlation between the children's attachment quality (AQS scores) and their selfevaluation (PSES averages) show a practically significant correlation $\left(r_{s}=.40, p=.24\right)$ for these 10 participants.

\section{Correlation between Attachment Quality (AQ) and Cognitive Development (CD) (see Table 2)}

After computing Spearman's rank-order coefficient on the security scores of the AQS and the Age equivalent scores of the GMDS-ER, for examination of the correlation between $A Q$ and $C D$, results showed a practically significant $\left(r_{s}=.46, p=.17\right)$ relationship between variables. Effect sizes reflect that the correlation is practically significant for the 10 dyad pairs. 


\section{Correlation between Self-Evaluation (SE) and Cognitive Development (CD) (see Table 2)}

Examination of the correlation, Spearman's rank-order coefficient, between the children's self-evaluation (SE) and their cognitive development (CD) indicated a large effect $\left(r_{s}=.61, p=.06\right)$. For all practical purposes the effect sizes indicate that the correlation between the average scores of the PSES and the Age equivalent scores of the GMDS-ER are significant for the 10 children in this study.

\section{Correlation between Attachment Quality (AQ) and the GMDS-ER Subscales (see Table 2)}

The quality of child-caregiver relationship (AQ) correlated with several of the GMDS-ER subscales. The Personal/Social subscale shows a practically significant correlation $\left(r_{s}=\right.$ $.42, p=.22$ ) towards attachment quality (AQS) scores. Correlation between AQS scores and the Language subscale show statistical significance $\left(r_{s}=.68\right)$ at the .05 level. For all practical purposes the effect sizes indicate that the correlation between the security scores of the AQS and Subscale F (Practical Reasoning) $\left(r_{s}=.54, p=.10\right)$ are significant.

\section{Correlation between Self-Evaluation (SE) and the GMDS-ER Subscales (see Table 2)}

The third subscale (Language) of the GMDS-ER indicates statistical significant correlation $\left(r_{s}=64, p<=0.05\right)$ with the PSES averages (SE). For all practical purposes the effect sizes of the Eye and Hand Coordination-, Performance-, and the Practical Reasoning subscale show significance, $r_{s}=.49(p=.14) ; r_{s}=.40(p=.24)$; and $r_{s}=.56(p=$ .09) respectively, in their correlation with the average scores of the PSES (SE) for the 10 children.

\section{Correlation between Cognitive Development (CD) and the GMDS-ER Subscales (see Table 2)}

Subscale A (Locomotor) of the GMDS-ER is the only subscale that showed practical significant correlations $\left(r_{s}=.55, p=.10\right)$ with the GMDS-ER age equivalent scores (CD). Correlation between CD (GMDS-ER age equivalent scores) and the remaining GMDSER subscales show statistical significant correlations at a .01 level. Effect sizes are as follows; Personal/Social subscale $\left(r_{s}=.80\right)$, Language subscale $\left(r_{s}=.77\right)$, Eye and Hand Coordination subscale $\left(r_{s}=.84\right)$, Performance subscale $\left(r_{s}=.90\right)$, Practical Reasoning subscale $\left(r_{s}=.95\right)$ for the 10 participants.

\section{Discussion}

As intended by the present study, existence of positive correlations between attachment quality, self-evaluation and cognitive development were confirmed. Correlations between the measurements did not show any statistical significance, but an overall medium to large practical significance was obtained for these participants. When considering results, one needs to keep in mind the individual and the context in which that individual functions. Results can never be viewed in isolation. Marvin and Stewart (1993, p. 34) formulate it as "a whole adds the property of relationship among the parts." There is never one single cause for an effect; it's usually far more complex. 
In this study more secure attachment relationships, between the children and their mothers, have been found to positively correlate with higher global self-worth of the children. Similar results have been found, but no study combined these three important variables (Cassidy, 1988; Easterbrooks \& Goldberg, 1993; Verschueren \& Marcoen, 1999; Verschueren et al., 1996). Establishing a secure attachment relationship with the mother has an effect on how children evaluate themselves. In previous studies done by Verschueren and Marcoen (1999; 2002) positiveness of self and global self-worth showed the highest correlation with the security to the mother. Even though clarity in connection with the development of the self before age eight is not yet established (Carens \& Verschueren, 2000), Bowlby (1969/1982) suggested that a global sense of worth develops in conjunction with the early child-mother relationship, based on established IWM's of their daily experiences. Being able to use the mother as a secure base for exploration increase one's own level of competency (Marvin \& Stewart, 1993) and could contribute to the representation of the self (Verschueren \& Marcoen, 1999). The earliest relationships and environments of individuals therefore, "provide the context for the emergence of self" (Schneider-Rosen, 1993, p. 187). This early relationship is, therefore, important for concurrent and latter adaptation (Marvin \& Stewart, 1993) and self-esteem development (Brown et al., 2001).

As expected, this study indicated that a more secure attachment correlate with age appropriate cognitive development. The quality of the relationship formed between child and mother has implications for later development (Grossmann et al., 2002; Verschueren \& Marcoen, 1999). During developmental transitions of children the attachment relationship may be temporarily disrupted (Ainsworth, 1993) with a decrease in security as a result (Marvin \& Stewart, 1993). Homeostasis needs to be established for the relationship to stabilise again. Although attachment behaviour changes with development, IWM's of the early child-mother relationship are still at play to establish proximity and contact (Marvin \& Stewart, 1993) despite situational variation (Cassidy, 1993). Positive IWM's and the ability to still use the primary caregiver as a secure base promote exploration, autonomy, social activity and the mastering of these new developmental tasks (Easterbrooks \& Goldberg, 1993; Kail \& Cavanaugh, 2010; Schneider-Rosen, 1993). The inability to do so will predict less optimal functioning during these periods of change (Easterbrooks \& Goldberg, 1993). According to Sroufe (1979, p. 835) "exploration of the new has adaptive advantage." Children with a secure attachment move further away from their primary caregiver; communicate over larger distances; (Fairchild, 2006; Schneider-Rosen, 1993) and start to communicate their goals that put them in a goal-corrected relationship with their attachment figure (Bowlby, 1969/1982). Attachment theory predicts that "the quality of attachment is related to the child's cognitive and language development" (Verschueren \& Marcoen, 1999, p. 197). With the latter in mind it is clear why the Language subscale of the GMDS-ER showed such a strong correlation with more secure child-mother attachment relationship scores. Further positive correlations were found between the quality of attachment scores and the Personal/Social- and the Practical Reasoning subscale. Attachment theory implies that security of the attachment relationship 
has important implications in concurrent and later social functioning (Verschueren \& Marcoen, 2002). Establishing an attachment relationship is a critical socio-emotional task (during infancy) that creates a basis for competence, effective functioning and successful transition through the different developmental tasks in the socio-emotional and cognitive domains (Bowlby, 1969/1982; 1973/1991; 1980; Easterbrooks \& Goldberg, 1993). Going to pre-school, for example, with positive IWM's of a secure attachment relationship can increase pre-schooler's ability to use their teacher as a subordinate attachment figure which will improve development of alternative skills because the child is able to operate independently from the mother for extended periods of time (Marvin \& Stewart, 1993).

While controlling for perceived competence, a positive relation between selfevaluation and cognitive development was obtained. According to Cassidy (1993, p. 87), "self-related beliefs and feelings play a key role in development." This group's evaluation of their abilities and attributes (Brown et al., 2001) were found to be an indicator of their cognitive ability at the time of evaluation. Thinking about oneself in more positive ways, therefore, has a positive influence on cognitive development. The PSES scores correlated with several of the GMDS-ER subscales. The Language subscale is the most intellectual subscale in the GMDS-ER (Luiz, Barnard et al., 2006). The significant correlation between the Language subscale and the self-evaluation scores confirms Harter's (1990) claim that children require cognitive ability to verbalise their sense of self. According to Schneider-Rosen (1993), language and the expression thereof are of great importance in relationships and play a role in the feelings about the self and others in these relationships. Correlations between the PSES scores and the GMDS-ER subscales; Eye and Hand Coordination and Performance, could be explained by the fact that pre-schoolers define themselves with respect to their physical characteristics (which are observable and concrete), their preferences and their competencies (Kail \& Cavanaugh, 2010). Viewing themselves as valuable and worthwhile (Cassidy, 1993), pre-school children may start to believe more in their own ability to make plans and solve real-life situations (Kail \& Cavanaugh, 2010). This practical ability to act for the self may explain the correlation between PSES scores and the Practical Reasoning subscale. Although statistical significant scores were not obtained in the correlation between these reliabilities, this study demonstrates potential in reporting effect sizes.

It is clear that these variables have an influence on each other since infancy and therefore remain of importance when considering preventional work concerning attachment and development (on multiple levels, for example the formation of the self).

\section{Limitations and suggestions for further research}

The first limitation of this study would be the small number of participants. Future research with a larger sample size $(n>30)$ holds great potential. Secondly, the results of this study cannot be generalized to other five-year-olds, for participants did not represent a true random sample of this population in Potchefstroom, South Africa. 
The third limitation of the study was that global self-worth was measured via selfreported methods which may have limited the truthfulness of the answers based on the uncertainty about children's cognitive ability to verbalise their sense of self (Harter, 1990). Future researchers can benefit from including another self-worth measurement, completed by the parents or a teacher, for triangulation purposes. Another limitation was the lack of trained AQS individuals in South Africa, which compromised interobserver reliability. Comparative discussions, of the results, were also limited due to the lack of attachment studies conducted in a South African context. Finally, future research on the subscales of the GMDS-ER, in connection with self-evaluation and attachment quality, will contribute to a greater understanding of these initial findings.

\section{Acknowledgement}

A sincere note of gratitude goes out to Paula Sterkenburg and the Vrije Universiteit Amsterdam who created the opportunity for the first author to acquire the skills (at the Department of Clinical Child and Family Studies, VU University Amsterdam) needed to administer The Observed Attachment Behaviour Q-set. Gratitude also go to Paula Sterkenburg, Carlo Schuengel and Mirjam Oosterman for their assistance and input towards the initiation of this pilot study.

\section{Endnotes}

1. Expansion on the different factors over extends the scope of this research. This article will focus only on three distinctive factors, namely; the quality of the attachment, self-evaluation and cognitive development.

2. Identification criteria for primary caregiver were as follows: When the child is for instance (1) tired, (2) scared, (3) hungry or (4) hurt to which parent will he/she go first?

3. After infancy there is a decrease in physical proximity and contact. Older children "increasingly organise their intimate interactions with their attachment figures on the basis of physical orientation, eye contact, nonverbal expressions, and affect, as well as conversations about personal matters" (Marvin \& Britner, 2008, p. 57).

4. Selection criteria were as follows: (a) The pre-school child must be between 60 and 72 months old at the time of testing; (b) The pre-school child lives with his/her biological parents since birth; (c) The pre-school child's mother tongue is Afrikaans or English.

5. The English version of the PSES was translated to Afrikaans by a bilingual individual and then back-translated to English where after the original English version were compared with the back-translation and appropriate changes were made. The final versions were edited before it was used.

\section{References}

Ainsworth, M.D.S. (1969). Object relations, dependency, and attachment: A theoretical review of the infant-mother relationship. Child Development, 40(4), 969-1025.

Ainsworth, M.D.S. (1993). Some considerations regarding theory and assessment relevant to attachment beyond infancy. In M.T. Greenberg, D. Cicchetti and E. 
M. Cummings (Eds.). Attachment in the preschool years: Theory, research and intervention, p. 463-488. Chicago: University of Chicago Press.

Ainsworth, M.D.S. \& Bowlby, J. (1991). An ethological approach to personality development. American Psychologist, 46, 333-341.

American Psychological Association. (1992). Ethical principles of psychologists and code of conduct. American Psychologist, 47(12), 1597-1611.

American Psychological Association. (2001). Publication manual of the American Psychological Association ( $5^{\text {th }}$ ed.). Washington, DC: American Psychological Association.

Bakermans-Kranenburg, M.J. \& Van IJzendoorn, M.H. (2007). Research review: Genetic vulnerability or differential susceptibility in child development: The case of attachment. Journal of Child Psychology and Psychiatry, 48(12), 1160-1173.

Bless, C. \& Kathuria, R. (1998). Fundamentals of social statistics: An African perspective. Cape Town: Juta \& Co.

Bowlby, J. (1969/1982). Attachment and loss: Vol. 1. Attachment. NY: Basic Books.

Bowlby, J. (1973/1991). Attachment and loss: Vol. 2. Separation: Anxiety and anger. NY: Basic Books.

Bowlby, J. (1979). The making and breaking of affectional bonds. London: Tavistock.

Bowlby, J. (1979/2005). The making and breaking of affectional bonds: With new introduction by Richard Bowlby. NY: Routledge.

Bowlby, J. (1980). Attachment and loss: Vol. 3. Loss, sadness and depression. NY: Basic Books.

Bowlby, J. (1988/2005). A secure base: Clinical applications of attachment theory. NY: Routledge.

Boris, N.W., Aoki, Y. \& Zeanah, C.H. (1999). The development of infant-parent attachment. Infants and Young Child, 11(4), 1-10.

Boris, N.W., Zeanah, C.H., Bernet, W., Bukstein, M.D., Arnold, C., Arnold, V. et al. (2005). Practice parameter for the assessment and treatment of children and adolescents with reactive attachment disorder of infancy and early childhood. Journal of the American Academy of Child \& Adolescent Psychiatry, 44(11), 1206-1219.

Bretherton, I. \& Munholland, K.A. (2008). Internal working models in attachment relationships: Elaborating a central construct in attachment theory. In J. Cassidy and P.R. Shaver (Eds.). Handbook of attachment: Theory, research, and clinical applications, p. 102-129. NY: The Guilford Press.

Brisch, K.H. (2002). Treating attachment disorders: From theory to therapy. NY: The Guilford Press.

Bronfenbrenner, U. (1986). Ecology of the family as a context for human development: Research perspective. Developmental Psychology, 22(6), 723-742. 
Brown, J.D., Dutton, K.A. \& Cook, K.E. (2001). From the top down: Self-esteem and selfevaluation. Cognition and Emotion, 15(5), 615-631.

Burgess, R.L. \& MacDonald, K. (2004). Evolutional perspectives on human development ( $2^{\text {nd }}$ ed.). Thousand Oaks, CA: Sage.

Carens, M. \& Verschueren, K. (2000). Self-esteem, task choice and persistence in children: A cross-sectional study. Paper presented on achievement and task motivation, Leuven, Belgium.

Cassidy, J. (1988). Child-mother attachment and self in six-year-olds. Child Development, 59(1), 121-134.

Cassidy, J. (1993). Theoretical and methodological considerations in the study of attachment and the self in young children. In M.T. Greenberg, D. Cicchetti and E.M. Cummings (Eds.). Attachment in the preschool years: Theory, research and intervention, p. 87-119. Chicago: University of Chicago Press.

Cassidy, J. (2008). The nature of the child's ties. In J. Cassidy and P.R. Shaver (Eds.). Handbook of attachment: Theory, research, and clinical applications, p. 3-22. NY: The Guilford Press.

Cicchetti, D., Cummings, E.M., Greenberg, M.T. \& Marvin, R.S. (1993). An organizational perspective on attachment beyond infancy: Implications for theory, measurements, and research. In M.T. Greenberg, D. Cicchetti and E. M. Cummings (Eds.). Attachment in the preschool years: Theory, research and intervention, p. 3-49. Chicago: University of Chicago Press.

Cohen, J. (1990). Things I have learned (so far). American Psychologist, 45(12), 1304-1312.

Dekker, S.R. \& Schuengel, C. (2003-2004). Qsorter: Windows-based sorting and scoring of q-sort (version 3.0.0) [Computer software]. Amsterdam, The Netherlands: Vrije Universiteit \& Zetten. The Netherlands: OG Heldring.

De Kloet, E.R., Sibug, R.M., Helmerhorst, F.M. \& Schmidt, M. (2005). Stress, genes and the mechanisms of programming the brain for later life. Neuroscience and Biobehavioral Reviews, 29(2), 271-281.

DeMuller, E.K., Denham, S., Schmidt, M. \& Mitchell, J. (2000). Q-sort attachment process: Links from home to school. Developmental Psychology, 36(2), 274-282.

De Schipper, J.C., Stolk, J. \& Schuengel, C. (2006). Professional caretakers as attachment figures in day-care centers for children with disability and behavior problems. Research in Developmental Disabilities, 27(2), 203-216.

Diamond, G.M., Diamond, G.S. \& Hogue, A. (2007). Attachment-based family therapy: Adherence and differentiation. Journal of Marital and Family Therapy, 33(2), 177-191.

Dozier, M., Stovall, K.C., Albus, K.E. \& Bates, B. (2001). Attachment for infants in foster care the role of caregiver state of mind. Child Development, 72(5), 1467-1477.

Easterbrooks, M.A. \& Goldberg, W.A. (1993). Security of toddler-parent attachment: Relations to children's sociopersonality functioning during kindergarten. In M.T. Greenberg, D. Cicchetti and E.M. Cummings (Eds.). Attachment in the preschool years, p. 221-244. Chicago: University of Chicago Press. 
Ellis, S.M. \& Steyn, H.S. (2007). Nonparametric effect size measures. Paper presented at the annual conference of the South African Statistical Association, Muldersdrift, South Africa.

Fairchild, S.R. (2006). Understanding attachment: Reliability and validity of selected attachment measures for preschoolers and children. Child and Adolescent Social Work Journal, 23(2), 235-261.

Field, A. (2005). Discovering statistics using SPSS. London: Sage.

Gadeyne, E., Ghesquière, P., Onghena, P. \& Verschueren, K. (2000). Meten van zelfconcept bij jonge kinderen (Measuring self-concept of young children). Kind en Adolescent, 21(2), 125-143.

Goldberg, S. (2000). Attachment and development. London: Arnold.

Grantham-McGregor, S., Stewart, M. \& Powell, C. (1991). Behaviour of severely malnourished children in a Jamaican hospital. Developmental Medicine and Child Neurology, 33(8), 706-714.

Greenberg, M.T., Cicchetti, D. \& Cummings, M. (1990). Attachment in the preschool years: Theory, research and intervention. Chicago: University of Chicago Press.

Grossmann, K., Grossmann, K.E., Fremmer-Bombik, E., Kindler, H., Scheurer-Englisch, H. \& Zimmerman, P. (2002). The uniqueness of the child-father attachment relationship: Fathers' sensitive and challenging play as the pivotal variable in a 16-year longitudinal study. Social Development, 11(3), 307-337.

Harter, S. (1982). The perceived competence scale for children. Child Development, 53(1), 87-97.

Harter, S. (1990). Causes, correlates, and the functional role of global self-worth: A lifespan perspective. In J. Kolligian and R.J. Sternberg (Eds.). Competence considered, p. 67-97. New Haven, CT: Yale University Press.

Harter, S. \& Pike, R. (1984). The pictorial scale of perceived competence and social acceptance for young children. Child Development, 55(6), 1969-1982.

Hogrefe. (2008). GMDS-ER-2-8-Griffiths Mental Development Scales-Extended Revised: 2 to 8 years. Retrieved September 4, 2008, from http://www.hogrefe.co.uk/?/test/ show/111/.

Howe, D. (2005). Child abuse and neglect: Attachment, development and intervention. NY: Palgrave Macmillan.

Janssen, C.J.C., Schuengel, C. \& Stolk, J. (2002). Understanding challenging behaviour in people with severe and profound intellectual disability: A stress-attachment model. Journal of Intellectual Disability Research, 46(6), 445-453.

Johnson, S.C., Dweck, C.S. \& Chen, F.S. (2007). Evidence for infants' internal working models of attachment, Psychological Science, 18(6), 501-502.

Johnson, S.C., Dweck, C.S., Chen, F.S., Stern, H.L., Ok, S. \& Barth, M. (2010). At the intersection of social and cognitive development: Internal working models of attachment in infancy. Cognitive Science, 34(5), 807-825. 
Kail, R.V. \& Cavanaugh, J.C. (2010). Human development: A life-span view (5 ${ }^{\text {th }}$ ed.). Belmont, CA: Thompson/Wadsworth.

Luiz, D., Barnard, A., Knoesen, N., Horrocks, S., McAlinden, P., Challis, D. et al. (2006). Griffiths Mental Development Scales-Extended Revised (Two to eight years): Administration manual. Oxford: Hogrefe.

Luiz, D., Faragher, B., Barnard, A., Knoesen, N., Kotras, N., Burns, L.E. et al. (2006). Griffiths Mental Development Scales-Extended Revised (Two to eight years): Analysis manual. Oxford: Hogrefe.

Luiz, D.M., Foxcroft, C.D. \& Povey, J. (2006). The Griffiths scales of mental development: A factorial validity study. South African Journal of Psychology, 36(1), 192-214.

Luiz, D.M., Foxcroft, C.D. \& Stewart, R. (2001). The construct validity of the Griffiths scales of mental development. Child Care, Health and Development, 27(1), 73-83.

Lyons-Ruth, K., Alpern, L. \& Repaeholi, B. (1993). Disorganized infant attachment classification and maternal psychosocial problems as predictors of hostile-aggressive behaviour in the preschool classroom. Child Development, 64(2), 572-585.

Mann, C.J. (2003). Observational research methods. Research design II: Cohort, cross sectional, and case-control studies. Emergency Medical Journal, 20(1), 54-60.

Marvin, R.S. \& Britner, P.A. (2008). Normative development: The ontogeny of attachment. In J. Cassidy and P.R. Shaver (Eds.). Handbook of attachment: Theory, research, and clinical applications, p. 269-294. NY: The Guilford Press.

Marvin, R.S. \& Stewart, R.B. (1993). A family systems framework for the study of attachment. In M.T. Greenberg, D. Cicchetti and E.M. Cummings (Eds.). Attachment in the preschool years: Theory, research and intervention, p. 51-85. Chicago: University of Chicago Press.

Mennen, F.E. \& O'Keefe, M. (2005). Informed decisions in child welfare: The use of attachment theory. Children and Youth Services Review, 27(6), 577-593.

Mikulincer, M. \& Shaver, P.R. (2007). Boosting attachment security to promote mental health, prosocial values and inter-group tolerance. Psychological Inquiry, 18(3), 139-156.

Moss, E., Rousseau, D., Parent, S., St-Laurent, D. \& Saintong, J. (1998). Correlation of attachment at school age: Maternal reported stress, mother-child interaction, and behavior problems. Child Development, 69(5), 1390-1405.

Noar, S.M. (2003). The role of structural equation modeling in scale development. Structural Equation Modeling, 10(4), 622-647.

O'Connor, T.G. \& Croft, C.M. (2001). A twin study of attachment in preschool children. Child Development, 72(5), 1501-1511.

Pettit, G.S., Bates, J.E. \& Dodge, K.A. (1997). Supporting parenting, Ecological context, and children's adjustment: A seven-year longitudinal study. Child Development, 68(5), 908-923. 
Phillips, D.A. (1984). Illusions of incompetence among academically competent children. Child Development, 55(6), 2000-2016.

Phillips, D.A. (1987). Socialization of perceived academic competence among highly competent children. Child Development, 58(5), 1308-1320.

Rosenthal, R., Rosnow, R.L. \& Rubin, D.B. (2000). Contrasts and effect sizes in behavioural research: A correlational approach. Cambridge: Cambridge University Press.

Rusk, N. \& Rothbaum, F. (2010). From stress to learning: Attachment theory meets goal orientation theory. Review of General Psychology, 14(1), 31-43.

Rutter, M., O'Connor, T.G. \& English and Romanian Adoptees (ERA) Study Team. (2004). Are there biological programming effects for psychological development? Findings from a study of Romanian adoptees. Developmental Psychology, 40(1), 81-94.

Sander, L.W. (1976). Issues in early mother-child interaction. In E.N. Sander and A. Shapiro (Eds.). Infant psychiatry, p. 127-147. London: Yale University Press.

Sander, L.W. (1977). The regulation of exchange in the infant-caregiver system and some aspects of the context-content relationship. In M. Lewis and L.A. Rosenblum (Eds.). Interaction, conversation, and development of language, p. 133-158. NY: Wiley.

Schneider-Rosen, K. (1993). The development reorganization of attachment relationships: Guidelines for classification beyond infancy. In M.T. Greenberg, D. Cicchetti and E.M. Cummings (Eds.). Attachment in the preschool years: Theory, research and intervention, p. 185-219. Chicago: University of Chicago Press.

Schore, A.N. (2001). The effects of early relational trauma on right brain development, affect regulation, and infant mental health. Infant Mental Health Journal, 22(1-2), 201-269.

Schore, J.R. \& Schore, A.N. (2008). Modern attachment theory: The central role of affect regulation in development and treatment. Clinical Social Work Journal, 36(1), 9-20.

Schuengel, C., De Schipper, C. \& Sterkenburg, P. (2003). Hechtingsstoornissen en verstoorde gehechtheid [Attachment disturbances and disturbed attachment]. In S. Colijn, E.C.A. Collumbien, G. Lietaer, and R.W. Trijsburg (Eds.). Handboek integrative psychotherapie, Vol. 8.1, p. 1-24. Utrecht: De Tijdstroom.

Schuengel, C. \& Janssen, C.G.C. (2006). People with mental retardation and psychopathology. Stress, affect regulation and attachment. International Review of Research in Mental Retardation, 32, 229-260.

Schuengel, C., Voorman, J., Stolk, J., Dallmeijer, A., Vermeer, A. \& Becher, J. (2006). Selfworth, perceived competence, and behaviour problems in children with cerebral palsy. Disability \& Rehabilitation, 28(20), 1251-1258.

Schutt, R.S. (2006). Investigating the social world: The process and practice of research ( $6^{\text {th }}$ ed.). Thousand Oaks, CA: SAGE

Society for Research in Child Development. (2007). Ethical standards for research with children. Retrieved May 19, 2008, from http://www.srcd.org/ethicalstandards.html. 
Solomon, J. \& George, C. (2008). The measurement of attachment security and related constructs in infancy and early childhood. In J. Cassidy and P.R. Shaver (Eds.). Handbook of attachment: Theory, research, and clinical applications, p. 383-417. NY: The Guildford Press.

SPSS Inc. (2006). SPSS ${ }^{\circledR} 15.0$ for Windows, Release 15.0.0, Copyright ${ }^{\odot}$ by SPSS Inc. Chicago: Illinois.

Sroufe, L.A. (1979). The coherence of individual development: Early care, attachment, and subsequent development issues. American Psychologist, 34(10), 834-841.

Sroufe, L.A. (1988). The role of infant-caregiver attachment in development. In J. Belsky and T. Nezworski (Eds.). Clinical implications of attachment, p. 8-40. Hillsdale, NJ: Erlbaum.

Sroufe, L.A., Carlson, E.A., Levy, A.K. \& Egeland, B. (1999). Implications of attachment theory for development psychopathology. Development and Psychopathology, 11(1), 1-13.

Steyn, H.S. (2006). Handleiding vir die bepaling van effekgrootte-indekse en praktiese betekenisvolheid [Guidelines for determining of effect size indices and practical significance]. Noordwes Universiteit (Potchefstroomkampus), Potchefstroom. Retrieved August 5, 2008, from http://www.puk.ac.za/fakulteite/natuur/skd/ index.html.

Thompson, B. (1997). If statistical significance tests are broken/misused, what practices should supplement or replace them? Paper presented at the annual meeting of the American Psychological Association. Retrieved August 25, 2008, from http://eric. ed.gov./ERICDocs/data/ericdocs2sql/context.

Thompson, B. (2001). Significance, effect sizes, stepwise methods, and other issues: Strong arguments move the field. The Journal of Experimental Education, 70(1), 80-93.

Thompson, B. (2002a, April). What future quantitative social science research could look like: Confidence intervals for effect sizes. Education Researcher, p. 25-32.

Thompson, B. (2002b). 'Statistical', 'practical', and 'clinical': How many kinds of significance do counsellors need to consider? Journal of Counseling \& Development, 80, 64-71.

Thompson, R.A. (2008). Early attachment and later development: Familiar questions, new answers. In J. Cassidy and P.R. Shaver (Eds.). Handbook of attachment: Theory, research and clinical applications ( $2^{\text {nd }}$ ed.), p. 348-365. NY: Guilford Press.

Trusty, J., Thompson, B. \& Petrocelli, J.V. (2004). Practical guide for reporting effect size in quantitative research in the Journal of Counseling \& Development. Journal of Counseling \& Development, 82(1), 107-110.

Van IJzendoorn, M.H., Goldberg, S., Kroonenberg, P.M. \& Frenkel, O. (1992). The relative effects of maternal and child problems on quality of attachment: A meta-analysis of attachment in clinical samples. Child Development, 63(4), 840-858. 
Van IJzendoorn, M.H., Vereijken, C.M.J.L., Bakermans-Kranenburg, M.J. \& RiksenWalraven, J.M. (2004). Assessing attachment security with the Attachment Q-sort: Meta-analytical evidence for the validity of the observer AQS. Child Development, 75(4), 1188-1213.

Vaughn, B.E. \& Waters, E. (1990). Attachment behavior in the home and in the laboratory: Q-sort observations and strange situation classifications of one-yearolds. Child Development, 61(6), 1965-1973.

Vékony, A., Van Aggelen-Gerrits, M.H., Van Aken, M.A.G. \& Goudena, P.P. (2004). De relatie tussen zelfwaardering en gehechtheid aan ouders bij zevenjarige kinderen [The effect of attachment relationships on 7-year-olds' self-esteem]. Pedagogiek, 24(2), 124-137.

Verschueren, K., Buyck, P.\& Marcoen, A. (2001). Self-representations and socioemotional competence in young children: A 3-year longitudinal study. Developmental Psychology, 37(1), 126-134.

Verschueren, K. \& Marcoen, A. (1993a). Zelfbelevingsschaal voor Jonge Kinderen [Pictorial Self-Evaluation Scale]. Intern rapport. Katholieke Universiteit Leuven, Faculiteit Psychologie en Pedagogische Wetenschappen. Centrum voor Ontwikkelingpsychologie.

Verschueren, K. \& Marcoen, A. (1993b). Zelfbelevingsschaal voor Jonge Kinderen [Pictorial Self-Evaluation Scale]. Administration manual. Katholieke Universiteit Leuven, Faculiteit Psychologie en Pedagogische Wetenschappen. Centrum voor Ontwikkelingpsychologie.

Verschueren, K. \& Marcoen, A. (1999). Representation of self and socioemotional competence in kindergartners: Differential and combined effects of attachment to mother and to father. Child Development, 70(1), 183-201.

Verschueren, K. \& Marcoen, A. (2002). Perceptions of self and relationship with parents in aggressive and nonaggressive rejected children. Journal of School Psychology, 40(6), 501-522.

Verschueren, K., Marcoen, A. \& Schoefs, V. (1996). The internal working model of the self, attachment, and competence in five-year-olds. Child Development, 67(5), 2493-2511.

Waters, E. (1987). Attachment Q-set (Version 3). Retrieved January 22, 2007, from http://www.johnbowlby.com.

Waters, E. \& Deane, K. (1985). Defining and assessing individual differences in attachment relationships: Q-methodology and the organization of behavior in infancy and early childhood. In I. Bretherton and E. Waters (Eds.). Monographs of Society for Research in Child Development, 50(1-2), 41-65. 